\title{
COPD: The role of primary care in effective diagnosis, treatment and management
}

\section{Onno CP van Schayck, Klaus F Rabe, Michael Rudolf}

\section{Summary}

Chronic obstructive pulmonary disease (COPD) is a major global problem and its prevalence is increasing; yet under- or misdiagnosis is widespread, possibly due to clinical misinterpretation of symptoms, or lack of symptom reporting by patients.
Increasing awareness of COPD, and the implementation of effective screening programmes and treatment strategies in primary care could significantly improve management of the disease.

\begin{abstract}
Introduction
COPD is frequently under- or misdiagnosed, ${ }^{1-7}$ but the scale of the problem is unclear, and attempts to address it raise further issues. Should we implement primary care screening programmes to diagnose COPD earlier? And if detected early, can anything be done to stop or slow disease progression? As the global health and cost implications of COPD, one of the few diseases whose prevalence is rising, continue to increase, awareness of the condition must be raised. Primary care can play a significant role in the management of COPD and other respiratory diseases. For example, Blainey reported that $74 \%$ of hospital admissions due to severe respiratory problems could have been prevented by more effective primary care. ${ }^{8}$ This review summarizes a symposium addressing these issues (COPD: The role of primary care in effective diagnosis, treatment, and management) held at the World IPCRG conference on 7 June 2002.
\end{abstract}

\section{COPD: a global epidemic}

COPD is the fastest rising cause of death in the developed world, and an increasing problem in the

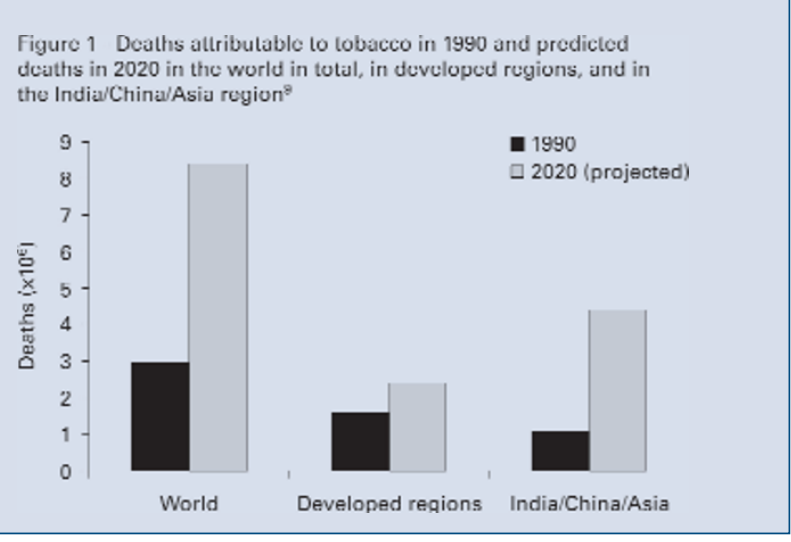

Figure 2 - Direct annual costs of chronic obstructive pulmonary disease in the USA, UK and Sweden 1214

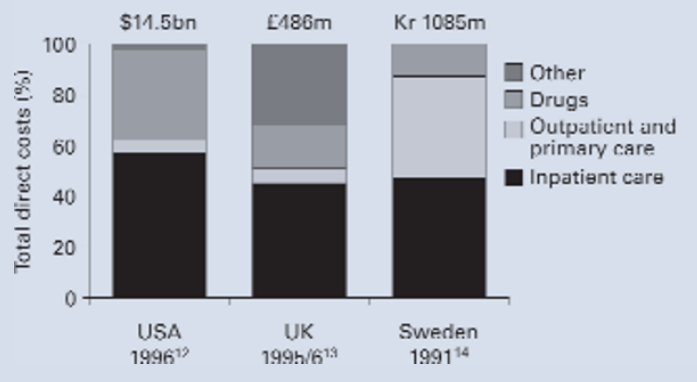
developing world. The Global Burden of Disease (GBD) study, ${ }^{9}$ initiated in 1992, predicted that COPD will rise from fifth place in 1990 to third in 2020 in the global ranking of causes of death (after ischaemic heart disease and cerebrovascular disease). The GBD study developed the internationally standardized concept of Disability Adjusted Life Year (DALY) to demonstrate disease impact on premature death and disability - it represents the sum of years of life lost because of premature mortality plus years of life lived with disability, adjusted for disability severity. Thus, one DALY is one year of healthy life lost. The study estimated that COPD will leap from the twelfth leading worldwide cause of DALYs in 1990 to the fifth in $2020 .^{9}$

\section{Smoking}

Smoking trends remain the most important predictor for COPD prevalence. Worldwide, deaths attributable to smoking are estimated to triple from 1990 to 2020, with tobacco expected to kill more people than any single disease (Figure 1). ${ }^{9}$ In developing areas of Asia, where tobacco smoking is just beginning to fully influence COPD prevalence, deaths will rise almost fourfold. Prolonged cigarette smoking causes more deaths by other diseases, such as vascular disease, than by lung cancer. ${ }^{10}$

China accounts for one-third of the world's cigarette consumption; between 1985 and 1992, consumption increased by $20 \%{ }^{11}$ Deaths attributable to smoking in China amount to 750,000 per year.

\section{Epidemiology}

The single largest management cost in COPD relates to hospital admissions and emergency care. ${ }^{12-14}$ Epidemiological studies show that inpatient care approximates half the direct costs attributable to COPD (Figure 2). Interestingly, outpatient and primary care costs in the USA and UK seem very low compared with inpatient care costs.

Indirectly, millions of working days are lost to COPD. In addition, lost productivity due to early retirement or death before retirement (up to $25 \%$ of deaths from COPD occur before retirement age) contribute to the enormous financial impact of COPD. ${ }^{13-15}$ For example, indirect costs associated with COPD were $£ 2,100$ million in the UK in $1995 / 6^{13}$ and 1699 million krona in Sweden in 1991. ${ }^{14}$

COPD has a greater impact on death rates and treatment costs than does asthma. ${ }^{16}$ COPD patients are more likely to be hospitalised, and for longer, than asthma patients. Furthermore, treatment costs rise dramatically with increasing disease severity.

The prevalence of COPD is probably underestimated, as many patients only seek medical advice at a late stage, when their symptoms become intolerable. Stang 


\section{Not to be reproduced without the permission of the Primary Care Respiratory Journal}

et al developed and validated a model, which estimated that, in the USA, over 15 million people have COPD (about $5.5 \%$ of the population), [US population estimated at 275 million in 2000 , therefore $5.5 \%$ of the population will have COPD based on 15 million having the disease] of whom between 56 and $85 \%$ remain undiagnosed. ${ }^{17}$

\section{Effective COPD identification in primary care} Improved detection methods and increased awareness in primary care may account for a proportion of the increase in recorded cases of COPD. In The Netherlands, the prevalence of airways disease increased from $19 \%$ in 1977 to $31 \%$ in 1992 , detected by screening the general population. ${ }^{18}$ Generally, only $25-50 \%$ of people with COPD are known to their primary care physician (PCP), ${ }^{17-19}$ so improved detection of COPD presents a major management challenge.

\section{Possible reasons for underdiagnosis of COPD}

PCPs may not recognise symptoms, while patients can become accustomed to their symptoms, and fail to present to their PCP. The Detection Intervention and Monitoring COPD and Asthma (DIMCA) project ${ }^{20}$ compared the underpresentation of symptoms with underdiagnosis by PCPs. From a random sample of 1,155 adults, $86(7 \%)$ had objective airflow obstruction, as measured by forced expiratory volume in 1 second $\left(\mathrm{FEV}_{1}\right)$, with symptoms suggestive of asthma or COPD. Only 29 (34\%) of these had ever presented to their PCP.

Also, patients may poorly perceive their own symptoms. For example, in the DIMCA project, 47 of the 86 people with reduced lung function were investigated further regarding their perception of dyspnea, ${ }^{20}$ as scored on the Borg scale during a histamine provocation test. 'Good' perceivers were defined as those in whom a decrease in $\mathrm{FEV}_{1}$ was accompanied by a Borg score increase. Of the 16 who did present to their PCP, only one was categorized as a 'poor' perceiver of dyspneoa, whereas $26 \%$ of the 31 people who had not presented to their PCP were 'poor' perceivers $(p=0.08$; Figure 3$) .{ }^{20}$

\section{Detecting COPD in primary care}

In most countries, PCPs are in a prime position to identify and diagnose COPD. How can this be achieved? Several studies have shown that general population screening is a possibility. $5,6,18,20$ The cost per detected case of COPD in one active screening programme was relatively low (\$564 per detected case) compared with screening programmes for other diseases, such as breast cancer $(\$ 5700-23,400$ per detected case)..$^{5}$ Case-finding among patients with known risk factors, such as smoking, may be a more effective approach. Typical COPD patients are usually over 40 years of age, are current or past heavy smokers, and have intermittent or daily cough and dyspnea that is worse upon exercise. Current smokers, who were not receiving pulmonary medication, were selected for a case-finding study in general practices in The Netherlands, ${ }^{21}$ and $18 \%$ were found to have airway obstruction $\left(\mathrm{FEV}_{1}<80 \%\right.$ predicted). Cough and age were found to be the most important predictors for detecting COPD in this population (Figure 4). A mean of 4 minutes were needed to assess 1 patient (including spirometry); it therefore took approximately 23 minutes to detect 1 patient with obstruction from this population of smokers, at a cost of $\square 5$ $\square 10$.

Spirometry is required to confirm the diagnosis of COPD (and to differentiate from asthma), and in addition may also be used to screen asymptomatic smokers. With appropriate training, practice assistants can measure lung function cost-effectively.

\section{Guidelines for effective} disease management The goals, according to the Global Initiative for Chronic Obstructive Lung Disease (GOLD)

Workshop Report, are to prevent disease progression, relieve symptoms, improve exercise tolerance, improve health status, prevent and treat complications/exacerbations, and reduce mortality. ${ }^{22}$ GOLD recommends a step-wise increase in treatment, depending on disease severity, as well as health education to help patients cope with their condition and improve their health status. ${ }^{23}$

\section{Delaying COPD progression}

Only smoking cessation has been proven to delay or halt COPD progression. Evidence suggests that the decline in lung function can be reversed when patients with mild-to-moderate COPD stop smoking. ${ }^{24,25}$ In the Lung Health Study (LHS), patients who stopped smoking experienced an average of $47 \mathrm{~mL}$

improvement in lung function $\left(\mathrm{FEV}_{1}\right)$ in the year after quitting, with an annual rate of decline in $\mathrm{FEV}_{1}$ comparable to that of people who had never smoked, and half that of patients who continued to smoke. ${ }^{26}$ Smokers are much more motivated to stop smoking when they know that they are at risk of developing a chronic lung disease such as COPD. ${ }^{27}$

Reducing smoking prevalence has likely cost benefits. A study estimating the healthcare costs of asthma and COPD in The Netherlands ${ }^{28}$ modelled three different scenarios of the impact of smoking cessation on COPD progression and projected illness costs:

1) a reference scenario, primarily predicting the impact of ageing;

2) an "attainable" health promotion-driven smoking 
reduction scenario; and

3) an "extreme" smoking reduction campaign scenario. The study predicted that smoking rates would fall from $32.8 \%$ in 1993 to $30.2 \%, 20.5 \%$ and $8.0 \%$, respectively, in 2010 for each scenario, and corresponding total direct medical costs of treatment would increase by $60 \%, 57 \%$ and $48 \%$ from 1993 to 2010 .

\section{Pharmacotherapeutic management of COPD}

Our understanding of the underlying disease processes of COPD has improved in recent years. COPD has an inflammatory component that attracts neutrophils and macrophages to the airways, triggering a cascade of events, including further recruitment of neutrophils, plasma leakage, increased mucus secretion and, ultimately, bronchoconstriction and dyspnoea. According to GOLD, COPD is a disease state characterised by airflow limitation that is not fully reversible. The airflow limitation is usually both progressive and associated with an abnormal inflammatory response of the lungs to noxious particles or gases. ${ }^{22}$ This definition acknowledges that there is a small reversible component in COPD, suggesting that this can and should be targeted with bronchodilator treatment. However, there is no known disease-modifying medication for COPD, and currently available pharmacotherapy mainly reduces symptoms and/or complications.

\section{Bronchodilators}

Inhaled bronchodilators are central to the symptomatic management of COPD, and are given to improve lung function and to relieve or prevent symptoms. ${ }^{22}$ The main bronchodilator classes are anticholinergics, 32 agonists, theophylline, or combination treatments, though some are more effective than others. For example, long-term treatment (12 months) with the long-acting 32 -agonist, formoterol (given as $12 \mu \mathrm{g}$ and $24 \mu \mathrm{g}$ ), was shown to be more effective at either dose than oral slow-release theophylline in improving airflow in COPD patients. ${ }^{29}$

Ipratropium, a four-times daily anticholinergic, and salmeterol, a twice-daily long-acting ß2-agonist, had similar peak $\mathrm{FEV}_{1}$ responses compared with placebo, ${ }^{30}$ though salmeterol gave a more consistent, continuous response because of its longer duration of action.

Long-term COPD clinical trials show that tiotropium maintenance therapy significantly improves lung function (measured by $\mathrm{FEV}_{1}$ and forced vital capacity $[\mathrm{FVC}]$ ) compared with placebo ${ }^{31}$ and ipratropium over 1 year. ${ }^{32}$ Another 6-month, placebo-controlled study confirmed the efficacy of tiotropium and salmeterol in improving lung function in COPD patients; however, after 6 months' treatment, $\mathrm{FEV}_{1}$ response was significantly greater with once-daily tiotropium than with twice-daily salmeterol $(\mathrm{p}<0.05) .{ }^{33}$ Tiotropium also demonstrated improvements in health status, being significantly superior to placebo in improving the St George's Respiratory Questionnaire ${ }^{34}$ Impacts domain and Total scores $(p<0.05)$, while salmeterol was not significantly different from placebo. ${ }^{33}$
However, another placebo-controlled trial showed that salmeterol $50 \mu \mathrm{g}$ twice daily, but not $100 \mu \mathrm{g}$ twice daily, did improve health status in COPD ( $\mathrm{p}=0.0007$ versus placebo). ${ }^{35}$ Additionally, a retrospective analysis of preliminary data from 1-year placebocontrolled studies suggested that tiotropium might reduce the decline in trough $\mathrm{FEV}_{1}$ compared with placebo. ${ }^{36}$ Further large, longer term studies are needed to confirm these observations.

\section{Inhaled corticosteroids}

The inflammatory process in COPD is physiologically different from that in asthma, ${ }^{37}$ and little evidence exists to support the use of inhaled corticosteroids (ICS) as maintenance therapy in COPD. Furthermore, long-term studies with ICS showed that they did not alter the rate of decline in lung function in COPD patients. ${ }^{26,38-41}$ GOLD guidelines recommend that regular ICS treatment be reserved for patients who have previously demonstrated a response to corticosteroids, and for those who have severe disease $\left(\mathrm{FEV}_{1}<50 \%\right.$ predicted) with repeated exacerbations requiring antibiotics and/or oral glucocorticosteroids. ${ }^{26,37,40,42}$

\section{Prevention and treatment of exacerbations in COPD}

Exacerbation prevention is now recognized as an important COPD treatment goal. ${ }^{43-45}$ One of the simplest means of reducing the risk of exacerbations in COPD is to ensure that all patients receive flu vaccination. ${ }^{46}$ Reducing the frequency and severity of exacerbations now appears to be possible with longterm bronchodilator and/or ICS treatment. ${ }^{30,32,40,41}$ For example, patients treated with tiotropium for 1 year had a reduced number of exacerbations $(24 \%$ reduction; $\mathrm{p}=0.006$ ) and fewer days with exacerbation (39\% reduction; $\mathrm{p}=0.002$ ) compared with patients treated with ipratropium. ${ }^{32}$ Additionally, there was a trend toward reductions in the number of hospitalisations and days spent in hospital due to COPD exacerbations compared with ipratropium. ${ }^{32}$ The reduction in exacerbations with tiotropium may be due to its continuous, 24-hour bronchodilation. Some studies have shown that the frequency and/or severity of exacerbations may be reduced with regular ICS use in patients with more severe COPD, ${ }^{40,41}$ while others have not shown benefit. ${ }^{38}$ Although short courses of systemic glucocorticosteroids can reduce exacerbation severity and duration, ${ }^{47}$ chronic administration should be avoided because of the high incidence of adverse events and their unfavourable benefit-to-risk ratio. ${ }^{48}$

Antibiotics are useful in exacerbations with a bacterial aetiology. A retrospective cohort analysis of 173 COPD patients showed a reduced relapse rate in patients who received antibiotics for their acute exacerbation of COPD compared with those who did not. 49

Other, non-pharmacological approaches to the management of COPD, such as pulmonary rehabilitation and exercise training programmes, may be beneficial in improving symptoms, exercise 
capacity and quality of life for COPD patients at all stages of disease. ${ }^{50}$

\section{Step-wise approach to treatment of COPD based on disease severity}

The GOLD committee has recommended therapy for each stage of COPD, based on evidence available at the time of publication (2001; Figure 5); ; $^{22}$ the first update is expected in early $2003 .^{51}$

"At risk" patients (Stage 0) with no spirometric abnormalities do not require treatment, other than smoking cessation advice.

For patients with mild disease (Stage 1), short-acting inhaled bronchodilators taken as needed may be sufficient to alleviate occasional symptoms.

In moderate disease (Stage 2A or 2B), patients probably have daily symptoms that restrict physical activity and impair quality of life, requiring additional maintenance therapy with long-acting inhaled bronchodilators, such as twice-daily formoterol ${ }^{29}$ or salmeterol. ${ }^{30}$ Once-daily tiotropium is not yet mentioned in the GOLD guidelines, but evidence from recent publications ${ }^{31-33}$ suggest its possible future inclusion as first-line maintenance therapy in COPD.

Rehabilitation and exercise training programmes should be undertaken in addition to pharmacotherapy by patients with moderate to severe disease. As discussed previously, regular treatment with inhaled glucocorticosteroids is recommended only for patients experiencing frequent exacerbations or with a documented spirometric response to corticosteroids. In advanced disease (Stage 3), when patients have unremitting symptoms despite maximal bronchodilator therapy, long-acting theophylline added to the preexisting maintenance therapy may provide additional benefit. Long-term oxygen therapy is advised for certain patients when chronic respiratory failure is present.

\section{Conclusions}

Although a major global healthcare problem, COPD is a treatable disease, and early diagnosis will allow steps to be taken to prevent or delay disease progression with smoking cessation. Healthcare professionals in primary care are ideally placed to play a significant role in effectively identifying COPD patients and delivering effective disease management.

\section{References}

1. Speight AN, Lee DA, Hey EN. Underdiagnosis and undertreatment of asthma in childhood. BMJ 1983;286:1253-

2. Levy M. Delay in diagnosing asthma - is the nature of general practice to blame? J R Coll Gen Pract 1986;36:52-3. 3. Brand PL, Rijcken B, Schouten JP, et al. Perception of airway obstruction in a random population sample.

Relationship to airway hyperresponsiveness in the absence of respiratory symptoms. Am Rev Respir Dis 1992;146:396-401. 4. Kendrick AH, Higgs CM, Whitfield MJ, et al. Accuracy of perception of severity of asthma: patients treated in general

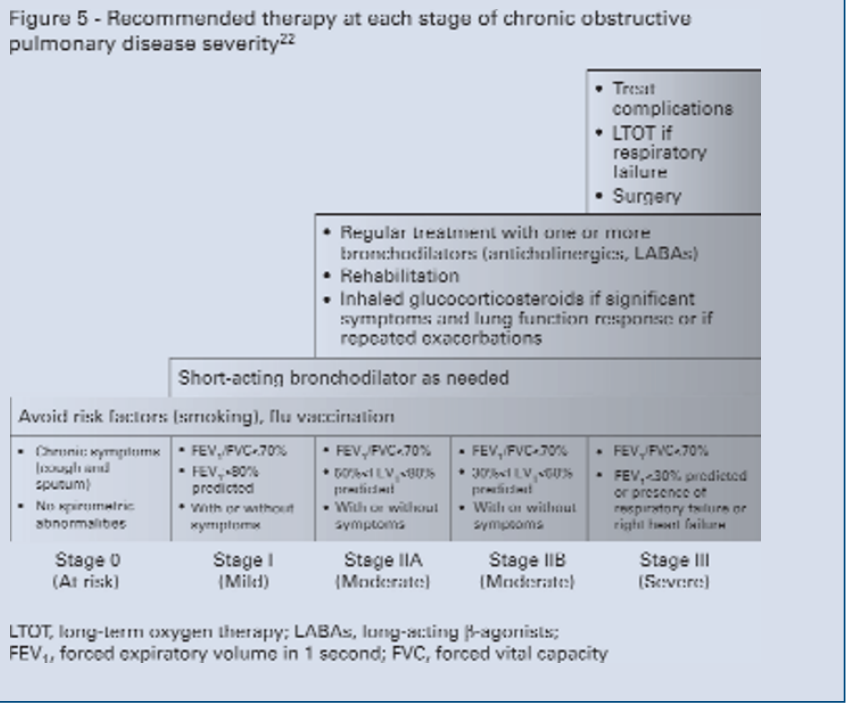

practice. $B M J$ 1993;307:422-4.

5. van den Boom G, van Schayck CP, Rutten-van Molken MPMH, et al. Active detection of chronic obstructive pulmonary disease and asthma in the general population. Results and economic consequences of the DIMCA program. Am J Respir Crit Care Med 1998;158:1730-8.

6. Zielinski J, Bednarek M. Know the Age of Your Lung Study Group. Early detection of COPD in a high-risk population using spirometric screening. Chest 2001;119:7316.

7. Rennard S, Decramer M, Calverley PM, et al. Impact of COPD in North America and Europe in 2000: subjects' perspective of Confronting COPD International Survey.Eur Respir J 2002;20:799-805.

8. Blainey D. The cost of acute asthma: how much is preventable? Health Trends 1990-91;22:151-3.

9. Murray CJL, Lopez AD. Alternative projections of mortality and disability by cause 1990-2020: Global burden of disease study. Lancet 1997;349:1498-1504.

10. Peto R, Lopez AD, Boreham J, et al. Mortality from tobacco in developed countries: indirect estimation from national vital statistics. Lancet 1992;339:1268-78.

11. World Health Organization. Smoking in China: A time bomb for the 21st Century. Fact Sheet No.177; August 1997. 12. Wilson L, Devine EB, So K. Direct medical costs of chronic obstructive pulmonary disease: chronic bronchitis and emphysema. Respir Med 2000;94:204-13.

13. Calverley P, Sondhi S. The burden of obstructive lung disease in the UK - COPD and asthma. Poster presented at the British Thoracic Society meeting - December 1998.

Thorax 1998;53(Suppl 4):A83.

14. Jacobson L, Hertzman P, Lofdahl CG, et al. The economic impact of asthma and chronic obstructive pulmonary disease (COPD) in Sweden in 1980 and 1991. Respir Med 2000;94:247-55.

15. National Heart Lung and Blood Institute, Morbidity and Mortality: 2000 Chartbook on Cardiovascular, Lung and Blood Diseases. 2000, US Department of Health and Human Services, Public Health Service, National Institutes of Health: Bethesda, MD, USA.

16. Murray C, Lopez A, eds. Global health statistics: a compendium of incidence, prevalence, and mortality estimates for over 200 conditions. Cambridge, MA, USA: Harvard University Press, 1996:672-5.

17. Stang P, Lydick E, Silberman C, et al. The prevalence of COPD. Using smoking rates to estimate disease frequency in 
the general population. Chest 2000;117:354S-9S.

18. Tirimanna PRS, van Schayck CP, den Otter JJ, et al. Prevalence of asthma and COPD in general practice in 1992: has it changed since 1977? Br J Gen Pract 1996;46:277-81. 19. Renwick DS, Connolly MJ. Prevalence and treatment of chronic airways obstruction in adults over the age of 45. Thorax 1996;51:164-8.

20. van Schayck CP, van der Heijden FMMA, van den Boom G, et al. Underdiagnosis of asthma: is the doctor or the patient to blame? The DIMCA project. Thorax 2000;55:5625 .

21. van Schayck CP, Loozen J, Wagena E, et al. Detecting patients at a high risk of developing chronic obstructive pulmonary disease in general practice: cross sectional case finding study. BMJ 2002;324:1370-4.

22. Pauwels RA, Buist AS, Calverley PMA, et al. Global strategy for the diagnosis, management, and prevention of chronic obstructive pulmonary disease. NHLBI/WHO Global Initiative for Chronic Obstructive Lung Disease (GOLD) Workshop Summary. Am J Respir Crit Care Med 2001;163:1256-76.

23. Celli BR. Pulmonary rehabilitation in patients with COPD. Am J Respir Crit Care Med 1995;152:861-4. 24. Anthonisen NR, Connett JE, Kiley JP, et al. Effects of smoking intervention and the use of an inhaled anticholinergic bronchodilator on the rate of decline of $\mathrm{FEV}_{1}$. JAMA 1994:272:1497-505.

25. Scanlon PD, Connett JE, Waller LA, et al. Smoking cessation and lung function in mild-to-moderate chronic obstructive pulmonary disease. The Lung Health Study. Am J Respir Crit Care Med 2000;161:381-90.

26. The Lung Health Study Research Group. Effect of inhaled triamcinolone on the decline in pulmonary function in COPD. N Engl J Med 2000;324:1960-1.

27. Humerfelt S, Eide GE, Kvale G, et al. Effectiveness of postal smoking cessation advice: a randomized controlled trial in young men with reduced $\mathrm{FEV}_{1}$ and asbestos exposure. Eur Respir J 1998;11:284-90.

28. Rutten-van Molken MPMH, Postma MJ, Joore MA, et al. Current and future medical costs of asthma and chronic obstructive pulmonary disease in The Netherlands. Respir Med 1999;93:779-87.

29. Rossi A, Kristufek P, Levine BE, et al. Comparison of the efficacy, tolerability, and safety of formoterol dry powder and oral, slow-release theophylline in the treatment of COPD. Chest 2002;121:1058-69.

30. Mahler DA, Donohue JF, Barbee RA, et al. Efficacy of salmeterol xinafoate in the treatment of COPD. Chest 1999;115:957-65.

31. Casaburi R, Mahler DA, Jones PW, et al. A long-term evaluation of once-daily inhaled tiotropium in chronic obstructive pulmonary disease. Eur Respir J 2002;19:217-24. 32. Vincken W, van Noord JA, Greefhorst APM, et al. Improved health outcomes in patients with COPD during 1 yr's treatment with tiotropium. Eur Respir J 2002;19:209-16. 33. Donohue JF, van Noord JA, Bateman ED, et al. A 6month placebo-controlled study comparing lung function and health status changes in COPD patients treated with tiotropium or salmeterol. Chest 2002;122:47-55.

34. Jones PW, Quirk FH, Baveystock CM, Littlejohns P. A self-complete measure of health status for chronic airflow limitation. The St. George's Respiratory Questionnaire. Am Rev Respir Dis 1993;145:1321-7.

35. Jones PW, Bosh TK. Quality of life changes in COPD patients treated with salmeterol. Am J Respir Crit Care Med
1997; 155:1283-9.

36. Anzueto A, Menjoge SS, Kesten S. Changes in FEV over time in one year clinical trials of tiotropium in COPD. Am J Respir Crit Care Med 2001;163:A280.

37. Jeffery PK. Structural and inflammatory changes in COPD: a comparison with asthma. Thorax 1998;53:129-36. 38. Vestbo J, Sorensen T, Lange P, et al. Long-term effect of inhaled budesonide in mild and moderate chronic obstructive pulmonary disease: a randomised controlled trial. Lancet 1999;353:1819-23.

39. Dompeling E, van Schayck C, van Grunsven P, et al. Slowing the deterioration of asthma and chronic obstructive pulmonary disease observed during bronchodilator therapy by adding inhaled corticosteroids. A 4-year prospective study. Ann Intern Med 1993;118:770-8.

40. Paggiaro PL, Dahle R, Bakran I, et al. Multicentre randomised placebo-controlled trial of inhaled fluticasone propionate in patients with chronic obstructive pulmonary disease. Lancet 1998;351:773-80.

41. Burge PS, Calverley PMA, Jones PW, et al. Randomised, double blind, placebo controlled study of fluticasone propionate in patients with moderate to severe chronic obstructive pulmonary disease: the ISOLDE trial. $B M J$ 2000;320:1297-303.

42. Pauwels RA, Lofdahl CG, Laitinen LA, et al. Long-term treatment with inhaled budesonide in persons with mild chronic obstructive pulmonary disease who continue smoking. N Engl J Med 1999;340:1948-53.

43. Donaldson GC, Seemungal TAR, Bhowmik A, Wedzicha JA. Relationship between exacerbation frequency and lung function decline in chronic obstructive pulmonary disease. Thorax 2002;57:847-52.

44. Andersson F, Borg S, Jansson SA, et al. The costs of exacerbations in chronic obstructive pulmonary disease (COPD). Respir Med 2002;96:700-8.

45. Miravitlles M, Murio C, Guerrero T, et al.

Pharmacoeconomic evaluation of acute exacerbations of chronic bronchitis and COPD. Chest 2002;121:1449-55. 46. Nichol K, Baken L, Nelson A. Relation between influenza vaccination and outpatient visits, hospitalization, and mortality in elderly persons with chronic lung disease. Annals of Internal Medicine 1999;130:397403.

47. Niewoehner D, Erbland M, Deupree R, et al. Effect of systemic glucocorticoids on exacerbations of chronic obstructive pulmonary disease. $N$ Engl J Med 1999;340:1941-7.

48. Decramer M, Lacquet L, Fagard R, et al. Corticosteroids contribute to muscle weakness in chronic airflow obstruction. Am J Respir Crit Care Med 1994;150:11-16.

49. Adams SG, Melo J, Luther M, et al. Antibiotics are associated with lower relapse rates in outpatients with acute exacerbations of COPD. Chest 2000;117:134552.

50. Berry M, Rejeski W, Adair N, et al. Exercise Rehabilitation and Chronic Obstructive Pulmonary Disease Stage. Am J Respir Crit Care Med 1999;160:1248-53.

51. Anon. The Science of COPD. GOLD Newsletter, June 2002.Vol. 1, No. 1

http://www.goldcopd.com/news june.pdf
Prim Care Resp J 2003; 12(1):16-20 